\title{
A STATISTICAL APPROACH TO SIMULATE INSTANCES OF ARCHEOLOGICAL FINDINGS FRAGMENTS
}

Submitted: $2^{\text {th }}$ June 2018; accepted $15^{\text {th }}$ January 2019

\author{
Fabrizio Renno, Antonio Lanzotti, Stefano Papa
}

DOI: 10.14313/JAMRIS_1-2019/6

\begin{abstract}
:
First aim of this paper is to describe a methodology developed to create virtual fragments of archeological archetypes in CAD (Computer Aided Design) environment. A simple Reverse Engineering (RE) technique was adopted to reconstruct the shape of vases allowing the archeologists, and so the CAD inexpert personnel, to use $i t$. Moreover, another relevant aspect is the definition of a procedure to simulate shape errors on the virtual prototypes to make more realistic the results. The characteristics of the fragments to be reproduced were selected by means of Design of Experiment (DOE) techniques. So, an algorithm was implemented to simulate the shape error, related to the working operations, that represents the typical noise for the feature recognition of archeological findings. Furthermore, this algorithm can make more complex the hypotheses related to the Gaussian model of simulation of the error and can adapt the value of the shape error (i.e. increasing it) according to the data gathered in archaeological excavation. The case study was based on the definition of a catalogue of archetypes of the black Campanian vases studied and classified by the archeologist J.P. Morel. The procedure conceived was applied to five (among one hundred) vases of the virtual catalogue obtaining forty instances of fragments affected by errors and so creating virtual mock-ups of typical pieces which may be found in the archeological site considered for the case study.
\end{abstract}

Keywords: Archetype, Profile Reconstruction, Geometric Modeling, Design of Experiments, Simulation of the shape and recognition errors

\section{Introduction}

The algorithms of recognition, reconstruction and classification of fragments in virtual environments have to be validated and optimized by means of wide test campaigns. Only in in this way, in fact, it is possible to demonstrate that the automated techniques can simplify the manual operations linked to the recognition and classification of thousands of fragments coming from an archeological site. Moreover, it is interesting to evaluate the benefits that can derive, for the study of 3D shapes of fragments initially not classifiable, from the use of automatic reconstruction and classification procedures [2-4]. The last ones can be included among the Virtual Prototyping Techniques widely spread from engineering to humanities fields [5-17].

To recognize and classify the fragments in virtual environments the archetypes to be used as references are needed. So, first step of the procedure, for the development of the cases studies, is the creation of the virtual catalogue and the CAD modeling of the archeological findings starting from the example of the Morel Catalogue [1]. Second step is the definition and the planning of the fragments to be simulated in order to use in the best way the information coming from results of the tests based on the recognition and classification techniques.

Furthermore, after the data gathered from the first phase of tests, the successive and more evolved experimentation can be planned [18]. Therefore, the paper is based on the following sections:

1. creation of the archetypes catalogue;

2. planning of the features of the virtual fragments;

3. simulation of the virtual fragments.

\section{Creation of the Archetypes Catalogue}

The archetypes of the virtual catalogue significantly represent the shapes of the black Campanian vases, both closed both open, found at the site of the "Santuario di Hera alla foce del Sele". In particular, the following parts were chosen from the Morel Catalogue (1981): convex and concave cups, inset lip, skyphoi, pitchers, lekythoi and situlae (Appendix A).

Moreover, the shape of a so-called "Standard vase" used as case study was defined according to the typical black Campanian vases of the Paestum area.

\subsection{Semiautomatic Vectorizing of the Profile}

The reconstruction of the profile of the vase is grounded on two phases:

I. acquisition by means of 2D scanner of the image of the vase or of the generic archaeological finding;

II. vectorizing of the acquired image.

The acquisition allows to get the digital image in a common raster (graphic) format (i.e. bmp, jpeg, tiff). In Figure 1 an example of 2D acquisition of a vase profile is depicted.

The vectorizing is a process that, starting from a raster image, allows the definition of lines, arcs and geometrical shapes that can be modified in CAD 


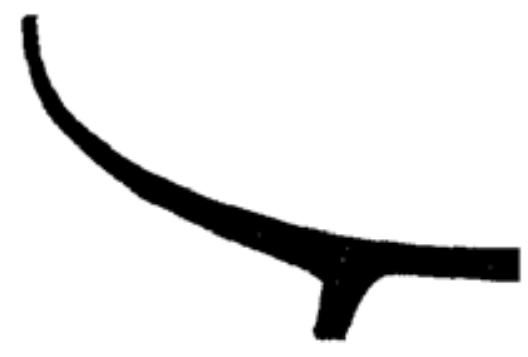

2912a 1

Fig. 1. Raster Image of the profile of a vase [1]

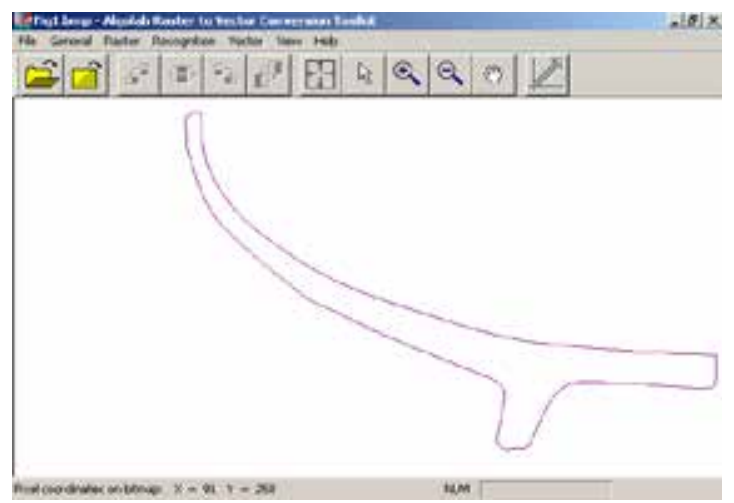

Fig. 2. Result of the vectorizing of the Figure 1 by means of the R2V software

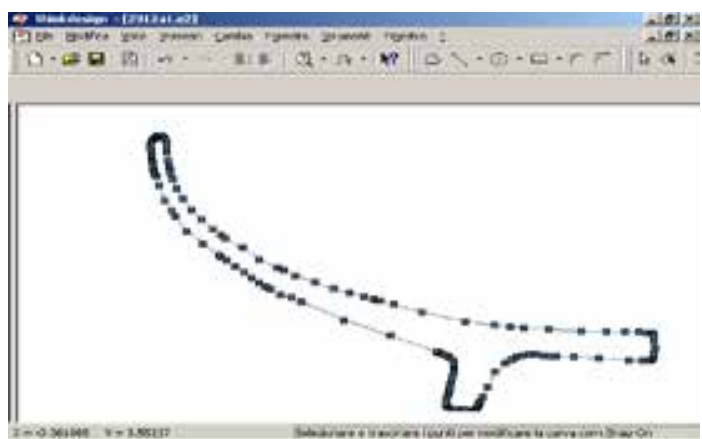

Fig. 3. Analysis of the B-Spline curve realized in the CAD environment

environment. These elements are called "Vector Drawing" [5]. It is possible to get it by means of specific software with "raster to vector" tools. In these environments, the typical CAD drawing elements as point, line, spline, polygon, rectangle, square, circle and text are available. Therefore, the obtainable results are vectors and so $2 \mathrm{D}$ entities. Usually, before to vectorize an image a pre-processing phase is needed to avoid errors. The scanning process, in fact, can acquire also noises as specks of dust or colour lacks can be generated (see Figure 1) making harder and complex the profile reconstruction defining wrong and unwanted geometric features. In particular, in this paper, the vectorizing phase by means of a specific freeware software (Algolab Photo Vector) is used and analysed. This kind of software allows to get the boundaries of the case study as set of spline arcs. In Figure 2 the vectorizing example of the boundary of a vase is shown. A preliminary optimization and so a "cleaning operation" of the image has be done to reduce the number of possible errors during the vectorizing phase. In the end, in Figure 3, the vectorized image of the vase, then imported in the CAD environment, is shown.

In particular, the CAD tools allow to analyse the curvature and if needed to simplify the geometry reducing the number of control points and of the cubic spline arcs that forms the B-Spline.

\subsection{Manual Vectorizing for the Reconstruction of the Profile}

An alternative technique for the reconstruction of the profile contemplates to use the (scanned) raster image as reference directly in the CAD environment. But in this case, it is required the knowledge of the main geometric rules on curves and surfaces to be used and in particular the expertise in the use of the specific CAD software adopted for the reconstruction process.

Once the image has been imported and located in respect of the reference system, it can be useful to plot auxiliary lines to better control and draw the profile shape. For instance, these lines can define the start and the end points of the profile.

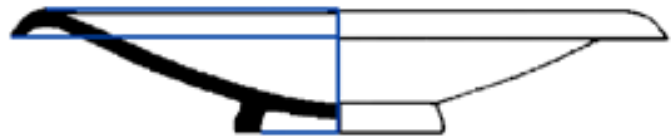

Fig. 4. Auxiliary lines used on the raster image imported in the CAD environment

Starting from the raster image it is possible to draw an overlapped control point curve defining the main points that the curve has to approximate (Figure 4). The adequate number of points can influence the continuity of the profile and it is determined by the CAD user and on the base of his expertise (Figure 5). The resolution of the image can affect the goodness of the process.

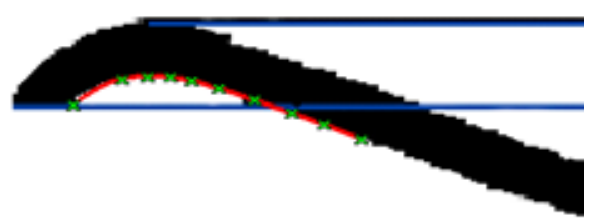

Fig. 5. External profile Approximated by means of a B-Spline and several control points

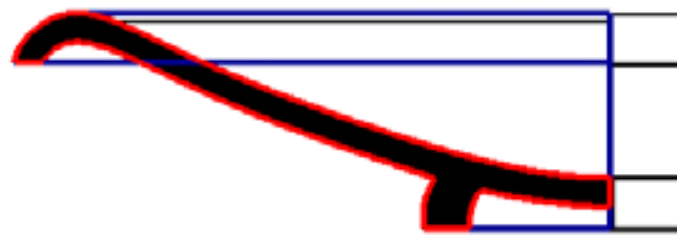

Fig. 6. Modeling of the profile by means of faired curves 
Afterwards, it is possible to model the curve reducing the degree of curvature, the number of arcs and of the points to be approximated. It allows to get the needed profile by means of a faired curve [16].

\subsection{Geometric Modeling}

The vectorized profiles of the virtual database are shown in the Appendix B. Starting from the 2D profiles it is possible to realize the $3 \mathrm{D}$ models of the vases by means of simple operations and features in CAD environment. The virtual reconstruction of the complete database can allow the setting up of a virtual museum available on the web.

The first step for the virtual reconstruction of the whole vase is the definition of the symmetry axis for the revolve of the profile. Then, the profile is drawn. So, the Figure 7 a shows the result of the image acquisition of the virtual catalogue, whereas the Figure $7 \mathrm{~b}$ points out the vectorized profile and the symmetry axis used as main reference.

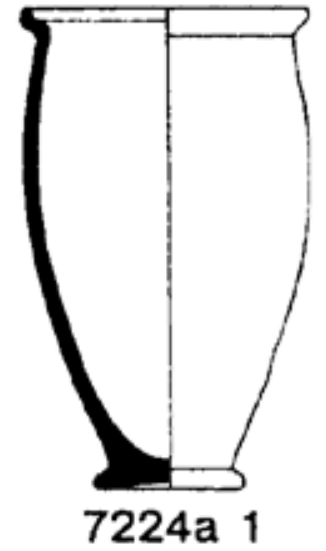

(a) (b)

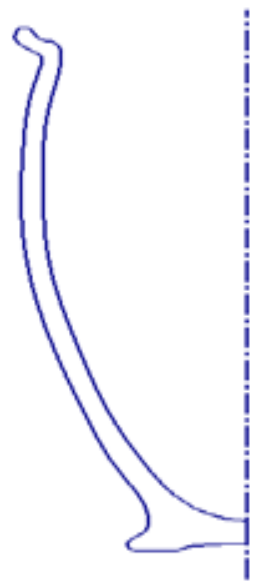

Fig. 7. (a) Raster image of a vase, (b) Vectorized profile (extrados and intrados) and symmetry axis

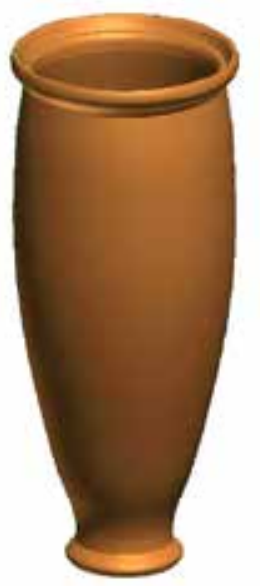

Fig. 8. 3D CAD solid model of the full vase

In Figure 8 the solid (CAD) model of the full vase obtained by means of a simple revolve feature is depicted.

So, considering the internal or external profile or both, it is possible to get the corresponding surface of the vase. Otherwise, starting from the full (closed) profile that represent the section of the vase it is possible to realize the 3D CAD reproduction of the vase by means of the solid modeling tools. Moreover, it allows to use the CAD to have detailed information about the volume, the mass and the other main mechanic characteristics of the final model.

\section{Planning of the Characteristics of Virtual Fragments}

To identify the characteristics of the fragments to be simulated, the DOE (Design of Experiments) techniques were employed. The advantage of this approach is widely documented [18-21]. Experimentation using experiments design techniques is articulated in seven basic steps:

1. definition of the problem;

2. choice of factors and levels;

3. choice of the response variable;

4. choice of the experimental plan;

5. conduct of experiments;

6. data analysis;

7. conclusions and planning of following experimental phases.

\subsection{Problem Definition}

The objective of the planning of the tests is the creation of simulated case studies, which allow the verification of the goodness of recognition and classification algorithms managing to define:

- the characteristics (or factors) that influence recognition and classification;

- the essential advantages of recognition and classification using 3D models compared to traditional manual techniques.

Then, knowing from which archetype the fragment analysed was extracted, it is possible to evaluate, for example, the percentage of correct/incorrect classification of the fragments.

\subsection{Choice of Factors and Levels}

The characteristics of the fragments taken into consideration are:

A. size of the fragment,

B. position on the vase,

C. orientation on the vase,

D. aspect ratio,

E. production error.

These characteristics are identified as factors of experimentation and for each of them the values to be tested are chosen, called levels (Table 1).

The size of the fragment is chosen equal to $0.5 \%$ or $2 \%$ of the whole vase in order to obtain small fragments and not immediately "speaking". As a consequence, starting from the total number of points that constitute a complete scan of good quality of the vase, the number of points relative to each of the two levels is obtained.

The position on the vase is defined on the basis of the area belonging to the profile with a small or large radius of curvature. With the choice of factors, the 
presence of particular geometric features that would make the recognition univocal (e.g. the foot or the upper edge) was excluded.

The orientation on the vase defines the arrangement of the long side of the fragment according to a meridian or a parallel.

The aspect ratio is the theoretical ratio between base and height, having chosen rectangular fragments, and can assume values close to one or two times the golden ratio. With regard to the choice of the rectangular shape of the point clouds, the simplified hypothesis is made of considering the maximum rectangle inscribed in the real geometry with an irregular contour. This assumption is generally conducted to verify the reconstruction algorithms.

The production error is related to the deviation of the real geometry from the reference archetype of the vase. In our hypothesis the reference archetype (that is the nominal geometry) is reported in [1]. Since data on the variability of production of black paint Paestum vases are not available in the reference period, two natural tolerance values of $0.5 \mathrm{~mm}$ and $2 \mathrm{~mm}$ are assumed.

Tab. 1. Choice of factors and levels for fragment generation

\begin{tabular}{|c|c|c|c|}
\hline \multirow{2}{*}{ FACTORS } & \multicolumn{2}{c|}{ LEVELS } \\
\cline { 3 - 4 } A & $\begin{array}{c}\text { Fragment size } \\
\text { (percentage of vase) }\end{array}$ & $0.5 \%$ & $\mathbf{1}$ \\
\hline B & Position on the vase & $\begin{array}{c}\text { High } \\
\text { curvature } \\
\text { area }\end{array}$ & $\begin{array}{c}\text { Survature } \\
\text { area }\end{array}$ \\
\hline C & Orientation on the vase & $\begin{array}{c}\text { Along } \\
\text { a meridian }\end{array}$ & $\begin{array}{c}\text { Along } \\
\text { a parallel }\end{array}$ \\
\hline D & Aspect Ratio & $\sim 1.6$ & $\sim 3.2$ \\
\hline E & Production error & $0.5 \mathrm{~mm}$ & $2 \mathrm{~mm}$ \\
\hline
\end{tabular}

\subsection{Choice of the Response Variable}

The "phenomenon" [19] object of study is the ability of an algorithm to correctly assign to a class of vases the fragment reconstructed starting from a cloud of points acquired through laser digitizer. Since the information contained in the incomplete fragment, possible studied answers conce $\mathrm{n}$ the adequacy of the reconstruction of the fragment geometry and the correctness of the recognition of the archetype.

\begin{tabular}{|c|c|c|}
\hline $\begin{array}{c}\text { RECOGNITION, } \\
\text { INFORMATION } \\
\text { FRAGMENT THE }\end{array} \Rightarrow \begin{array}{c}\text { RECONSTRUCTION AND } \\
\text { CLASSIFICATION } \\
\text { ALGORITHMS }\end{array}$ \\
\hline
\end{tabular}

Fig. 9. From the fragment to the archetype through automated techniques

\subsection{Choice of the Experimental Plan}

For the choice of the experimental plan a fractional factorial plan $2_{\text {III }}^{5-2}$ was used to reduce the number of experiments from 32 to 8 (Table 2). The plan is of res- olution III [17]. In this way 8 experiments are planned for each of the chosen vases (Figure 10) among the 100 that make up the virtual catalogue, defining the 40 fragments proposed as case studies.

Tab. 2. Fractional factorial plan $2_{\mathrm{III}}^{5-2}$

\begin{tabular}{|c|c|c|c|c|c|}
\hline EXPERIMENT & \multicolumn{5}{|c|}{ FACTORS } \\
\hline & A & B & C & D & E \\
\hline $\mathbf{1}$ & 0 & 0 & 0 & 0 & 0 \\
\hline $\mathbf{2}$ & 0 & 0 & 0 & 1 & 1 \\
\hline $\mathbf{3}$ & 0 & 1 & 1 & 0 & 0 \\
\hline $\mathbf{4}$ & 0 & 1 & 1 & 1 & 1 \\
\hline $\mathbf{5}$ & 1 & 0 & 1 & 0 & 1 \\
\hline $\mathbf{6}$ & 1 & 0 & 1 & 1 & 0 \\
\hline $\mathbf{7}$ & 1 & 1 & 0 & 0 & 1 \\
\hline $\mathbf{8}$ & 1 & 1 & 0 & 1 & 0 \\
\hline
\end{tabular}

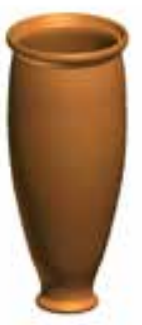

$7224 \mathrm{a} 1$

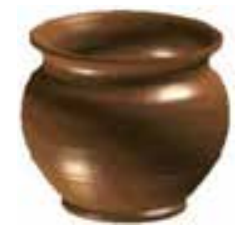

Standard

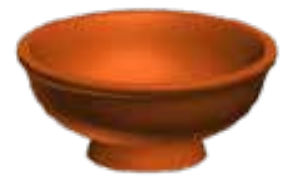

$2685 b 1$

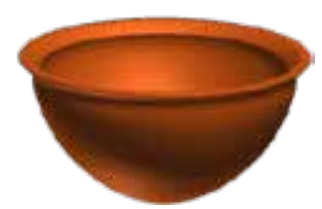

2122a1

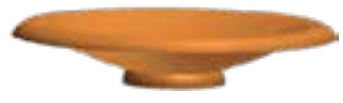

$1531 \mathrm{e} 1$
Fig. 10. Vases chosen as case studies

For example, by applying the fractional plane to the standard named vase, the characteristic levels of each of the eight experiments are obtained, hence the consequent selection of the fragments. The profile of this vase is made up of 170 points, one of which belongs to the axis of revolution, for a total of 60841 points of the whole vase. In this case, the percentage value of the dimension $(0.5 \%$ or $2 \%)$ gives the theoretical number of points of each fragment: 304 or 1217 points.

The level of the Aspect Ratio (theoretical B/H ratio close to one or two times the golden ratio) defines the lengths of the two sides. The other factors are univocally defined, except for the position whose final definition is left by the investigator. Figure 11 shows eight fragments corresponding to the experimental plan shown in Table 3 in the case study of the standard vase. 
Tab. 3. Experiments corresponding to the eight fragments

\begin{tabular}{lccccc}
\hline EXP. & \multicolumn{5}{c}{ FACTORS } \\
\hline & $\begin{array}{c}\text { Dimension } \\
\text { (\% of vase) }\end{array}$ & $\begin{array}{c}\text { Position } \\
\text { (Radius) }\end{array}$ & $\begin{array}{c}\text { Orientation } \\
\text { of the vase }\end{array}$ & $\begin{array}{c}\text { Aspect } \\
\text { Ratio } \\
\text { (B/H) }\end{array}$ & Error \\
$\mathbf{1}$ & $0.5 \%$ & High & Merid. & 1.618 & 0.05 \\
$\mathbf{2}$ & $0.5 \%$ & High & Merid. & $2 \times 1.618$ & 2 \\
$\mathbf{3}$ & $0.5 \%$ & Small & Paral. & 1.618 & 0.05 \\
$\mathbf{4}$ & $0.5 \%$ & Small & Paral. & $2 \times 1.618$ & 2 \\
$\mathbf{5}$ & $2 \%$ & High & Paral. & 1.618 & 2 \\
$\mathbf{6}$ & $2 \%$ & High & Paral. & $2 \times 1.618$ & 0.05 \\
$\mathbf{7}$ & $2 \%$ & Small & Merid. & 1.618 & 2 \\
$\mathbf{8}$ & $2 \%$ & Small & Merid. & $2 \times 1.618$ & 0.05
\end{tabular}

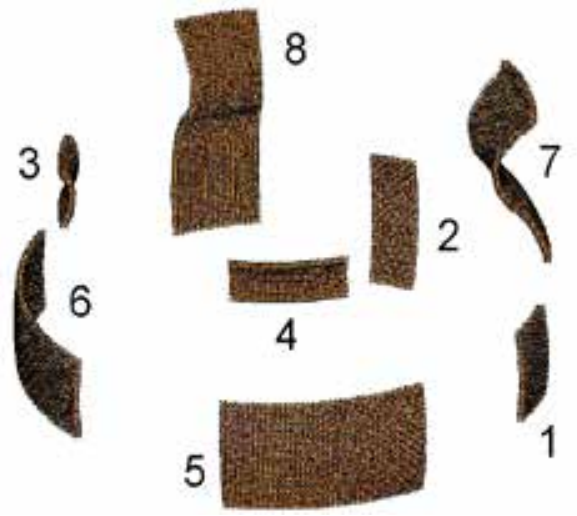

Fig. 11. Fragments of the standard vase

\section{Simulation of the Shape Error}

One of the factors considered in the simulation of fragments using DOE techniques is the shape error inevitably present in real products. To the shape error due to the production the measurement error is added, caused by the survey technique used. The use of laser digitizers makes the error of the acquisition negligible compared to that of production.

The technique of producing small series of artisanal vases on the lathe requires the realization of the desired shape by manually imposing the profile in the radial direction $(y)$, moving along the vertical direction $(\mathrm{x})$.

The simplified hypothesis made at the base of the simulation of this type of error are:

1. generation of the error in the radial direction, in the diametric plane xy;

2. constancy of the error along the circumference on the surface of the fragment.

\subsection{Nominal Profile and Simulated Profile}

Indicate with $y_{n}(x)$ the curve that explicitly represents the nominal profile of the vase and lies in the xy plane. Then, in the simplified hypothesis referred to in the previous paragraph, the simulated profile affected by error, $y_{s}(x)$, can be defined as follows:

$$
y_{s}(x)=y_{n}(x)+\varepsilon(x) \quad \text { con } x \in D_{x}
$$

where $\varepsilon(x)$ represents a normal steady variance process $\sigma_{\varepsilon}^{2}$.

It is known that, conventionally, the variance $\sigma_{\varepsilon}^{2}$ is linked to the natural tolerance of production from the relation:

$$
T_{n}=6 \sigma_{\varepsilon}
$$

from which, for example, for $T_{n}=2 \mathrm{~mm}$ a value of $s$ equal to $0.33 \mathrm{~mm}$ is obtained.

The s-independence hypothesis of the sections of the process, due to the production technology, cannot be formulated. Therefore, in general, it is possible to derive the combined probability density function of any two sections $\varepsilon(x)$ e $\varepsilon(x+\Delta x)$ and, distant $\Delta x$ from each other, as follows [20]:

$$
\begin{aligned}
& f(x, x+\Delta x)= \\
& =\frac{1}{2 \pi K_{\varepsilon \varepsilon}(0) \sqrt{1-\rho_{0}^{2}}} \exp \left[-\frac{x^{2}-2 \rho x(x+\Delta x)+(x+\Delta x)^{2}}{2\left(1-\rho_{0}^{2}\right) K_{\varepsilon \varepsilon}(0)}\right]
\end{aligned}
$$

where:

$$
\rho_{0}=\frac{K_{\varepsilon \varepsilon}(\Delta x)}{K_{\varepsilon \varepsilon}(0)}
$$

with

$$
K_{\varepsilon \varepsilon}(\Delta x)=E\{\varepsilon(x) \cdot \varepsilon(x+\Delta x)\}
$$

\subsection{Procedure for Generating Instances of Simulated Profiles}

In the study carried out the continuous curve of the profile was obtained, obtained by means of vectorization in a finite set of points identified through the $x$ and $y$ coordinates. In this way the acquisition process was simulated using laser digitizers, which in fact provide a cloud composed of a finite number of points (and proportional to the resolution).

In the hypothesis that:

a. the nominal profile is discretized into $n+1$ points $y_{n}(i)$ equi-spaced along the $x$ axis (so as to divide the interval $D_{x}$ into $n$ length intervals $\Delta x$ );

b. the error $\varepsilon(x)$ is represented by the simplest autoregressive model (AR (1)) [21]:

$$
\varepsilon_{i}=\rho \varepsilon_{i-1}+v_{i} \quad \text { con } i=1, \ldots, n
$$

where $\rho$ is the coefficient of autocorrelation $(-1 \leq \rho \leq 1)$ and $v i$ is the so-called white noise or pure error;

c. the pure error $v_{i}$ is a random variable Normal with mean 0 and variance $\sigma_{v}^{2}$ equal to:

$$
\sigma_{v}^{2}=\left(1-\rho^{2}\right) \sigma_{\varepsilon}^{2}
$$

the points of the simulated profile $y_{s}(i)$ are obtained starting from (1):

$$
y_{s}(i)=y_{n}(i)+\varepsilon_{i} \quad \text { con } i=1, \ldots, n
$$

with:

$$
y_{s}(0)=y_{n}(0)+v_{0} \text {. }
$$


For the considered model the error in each point of the profile is given by the sum ow two quote, the first directly proportional to the error in the previous point and the other merely random.
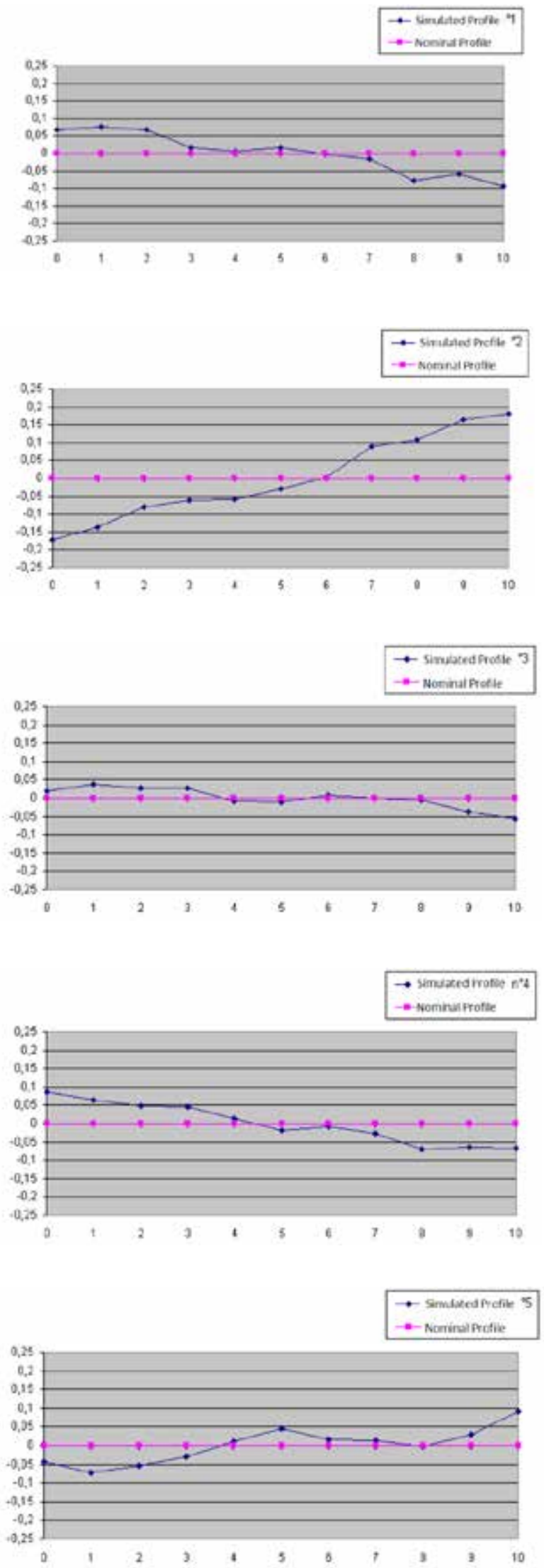

Fig. 12. Instances of the Simulated Profiles by means Monte Carlo method
To generate the pure error $v_{i}$ values, the Monte Carlo method was used, through which it is possible to simulate a random experiment to the computer, generating the results in a pseudo-random manner [19]. The result of the extraction of each set of pseudo-random numbers depends on the set seed. By varying the seed, it is possible to generate a predetermined number of replications of the same fragment, simulating its extraction from vases which, although belonging to the same type/class, are each different from the other due to the only production error. In this way, by fixing a sufficient number of replications, it is possible to evaluate the robustness of the classification algorithms in identifying a nominal profile based on the detected data that deviates from it (depending on the supposed error). The generation of the shape error, thanks to the extraction of pseudo-random numbers, provides, by means of (3) and (5), five different replications of the profile. If, for example, this method is applied to a rectilinear profile of $10 \mathrm{~mm}$, having divided it into 10 parts with a pitch of $\Delta x=1 \mathrm{~mm}$, the points $y_{n}(i)=0$ with $i=$ $0, \ldots, 10$ are obtained.

Figure 12 shows the five replications of simulated profiles $y_{s}(i)$ with $i=0, \ldots, 10$ that are obtained in the hypothesis that the natural tolerance assumes the value $0.5 \mathrm{~mm}$ (corresponding to the level 0 of the "production error" factor ) and therefore, from (2) and (4) the standard deviation of the pure error is equal to $0.026 \mathrm{~mm}$, having fixed the autocorrelation coefficient equal to 0.95 .

In the same way for the fragments, the procedure for extracting pseudo-random numbers was repeated with five different seeds, obtaining the five profiles of the considered fragment corresponding to the same experiment of the factorial plane and, therefore, characterized by the same factor levels.

\subsection{Simulation of Virtual Fragments}

The phase of acquisition of the geometry of a fragment allows obtaining a cloud of points to be processed using the reconstruction and classification algorithms (Figure 13a). In the simulation of fragments, fixed the characteristics of the test plan, the point clouds are generated directly or obtained from the solid model or by surface obtained by revolution (Figure 13b).

For the purposes of three-dimensional modeling, the position of the fragment on the vase (arranged along a profile area that has a large or small curvature radius) and the orientation on the vase (with the longer side along a meridian or along a parallel) are of interest: from these elements it is possible to identify the profile of the fragment that must rotate around the axis.

Consider, for example, the fragment corresponding to experiment 5 of the test plan (Table 3). It is defined by a cloud of 1217 points. Figure 14a shows the whole profile that defines the shape of the vase. Starting from the points, shown in Figure 14b, extracted from the whole profile the fragment identified by the factorial plane is reconstructed. By applying the procedure for generating simulated profiles, defined by 


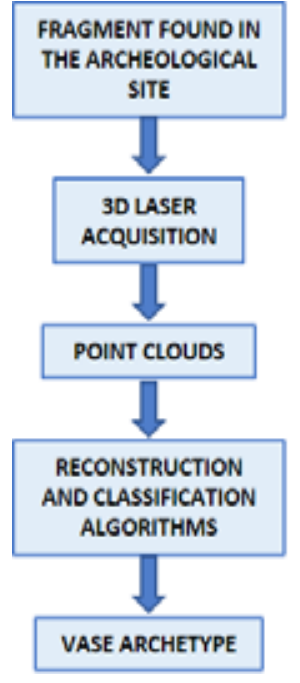

(a) Real Case

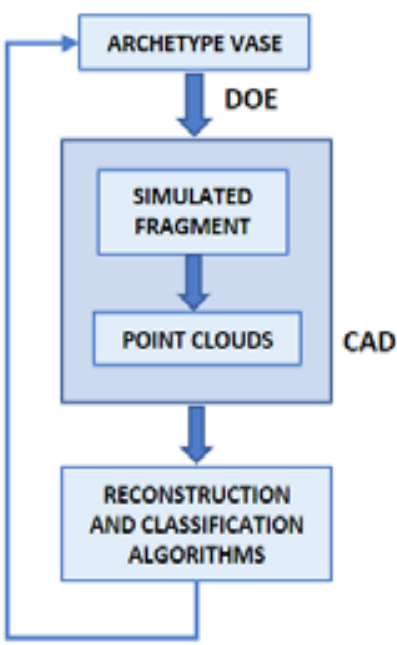

(b) Virtual Case
Fig. 13. From the fragment to the recognition of the archetype

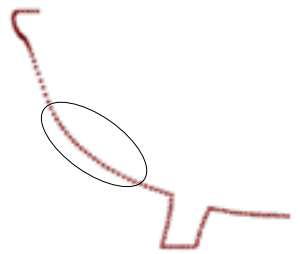

(a)

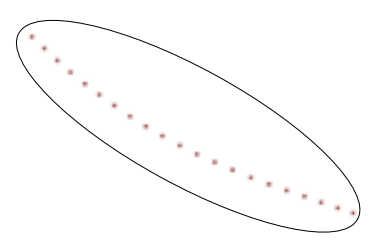

(b)
Fig. 14. Discretized profile and detail of the fragment with high curvature radius

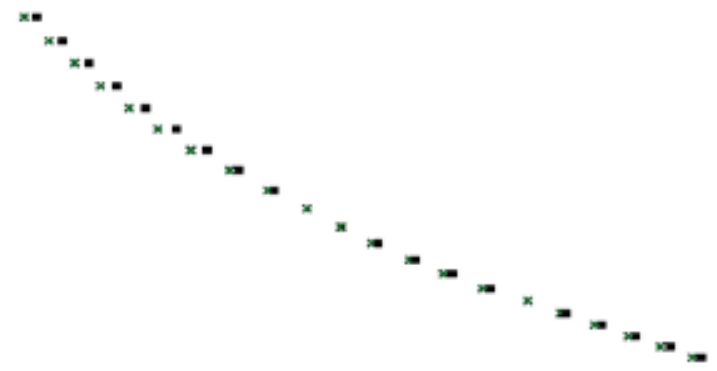

Fig. 15. Comparison between Nominal and Simulated (-) Profiles

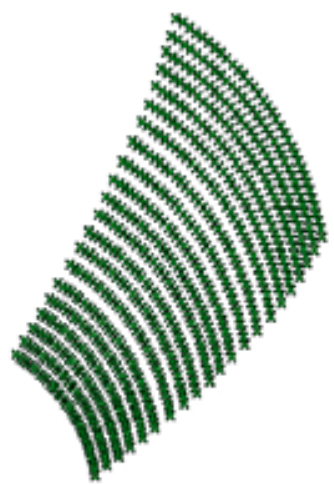

Fig. 16. Example of a Point Cloud of a simulated instance equation (5), the profile affected by error is obtained at the points of the nominal profile.

In Figure 15 the comparison between the nominal discretized and simulated profile is proposed by Monte Carlo.

Starting, therefore, from the simulated profile the revolution operation around the axis is realized defining an appropriate angular revolution step (Figure 16).

By means of a software for the surface reconstructon from point clouds, the fragment obtained can be visualized as a polygonal model (Figure 17). The program connects all the points of the cloud through segments and, therefore, builds triangles that allow to have a more realistic image of the fragment, with a more or less smooth surface.

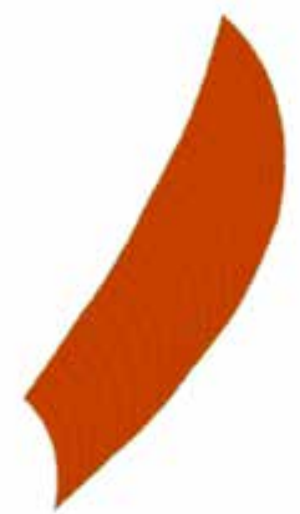

Fig. 17. Representation of the simulated fragment by means of the best fitting surface

\section{Conclusion}

The DOE techniques allow to deal with the problem of fragment simulation in a scientific way. The approach makes it possible to discover the robustness of automated recognition and classification algorithms and to set threshold values for fragment characteristics that make the use of Virtual Prototyping advantageous. This algorithm can make more complex the hypotheses related to the Gaussian model of simulation of the error and can adapt the value of the shape error (i.e. increasing it) according to the data gathered in archaeological excavation.

The study of the results of the first experiments may allow the planning of successive phases of experimentation in a virtual environment dedicated to the most influential characteristics on the reconstruction, recognition and classification of archaeological finds.

At the end, the results of the vectorizing phase of the case studies of the Morel Catalogue are shown in the Appendix B and are available for academics and students for research purposes by request to the authors.

\section{AUTHORS}

Fabrizio Renno* - Fraunhofer JL Ideas, Dipartimento di Ingegneria Industriale, Università degli Studi di Napoli Federico II, 80125 Naples, Italy, e-mail: fabrizio.renno@unina.it. 
Antonio Lanzotti - Fraunhofer JL Ideas, Dipartimento di Ingegneria Industriale, Università degli Studi di Napoli Federico II, 80125 Naples, Italy.

Stefano Papa - Fraunhofer JL Ideas, Dipartimento di Ingegneria Industriale, Università degli Studi di Napoli Federico II, 80125 Naples, Italy.

*Corresponding author

\section{ACKNOWLEDGMENTS}

The authors thank Dr. Maria Letizia Busiello for the archaeological consultancy and Eng. Giuseppe Sanso for the technical collaboration provided in the development of the simulation code.

\section{REFERENCES}

[1] J. P. M. Morel, Céramique campanienne: les formes, École Française de Rome, Palais Farnèse, 1981.

[2] C. Neamtu, S. Popescu, D. Popescu, and R. Mateescu, "Using reverse engineering in archaeology: ceramic pottery reconstruction", Journal of Automation Mobile Robotics and Intelligent Systems, vol. 6, no. 2, 2012, 55-59.

[3] F. Bruno, S. Bruno, G. D. Sensi, M.-L. Luchi, S. Mancuso, and M. Muzzupappa, "From 3D reconstruction to virtual reality: A complete methodology for digital archaeological exhibition", Journal of Cultural Heritage, vol. 11, no. 1, 2010, 42-49.

[4] G. Artese, L. D. Napoli, and S. Artese, "T.O.F. Laser Scanner for the Surveying of Statues: A Test on a Real Case". In: International Archives of the Photogrammetry, Remote Sensing and Spatial Information Sciences, vol. XL-5-W2, 2013, 67-72 DOI: 10.5194/ isprsarchives-XL-5-W2-67-2013.

[5] J. D. Foley, A. van Dam, S. K. Feiner, and J. F. Hughes, Computer Graphics: Principles and Practice, Addison-Wesley Longman Publishing Co., Inc.: Boston, MA, USA, 1990.

[6] S. Gerbino, D. M. Del Giudice, G. Staiano, A. Lanzotti, and M. Martorelli, "On the influence of scanning factors on the laser scanner-based 3D inspection process", International Journal of Advanced Manufacturing Technology, vol. 84, no. 9, 2016, 1787-1799

DOI: $10.1007 / \mathrm{s} 00170-015-7830-7$.

[7] A. Lanzotti, M. Grasso, G. Staiano and M. Martorelli, "The impact of process parameters on mechanical properties of parts fabricated in PLA with an open-source 3-D printer", Rapid Prototyping Journal, vol. 21, no. 5, 2015, 604-617 DOI: $10.1108 / \mathrm{RPJ}-09-2014-0135$.

[8] S. Patalano, A. Lanzotti, D. M. Del Giudice, F. Vitolo, and S. Gerbino, "On the usability assessment of the graphical user interface related to a digital pattern software tool", International Journal on Interactive Design and Manufacturing, vol. 11, no. 3, 2017, 457-469

DOI: 10.1007 /s12008-015-0287-y.
[9] A. Lanzotti, D. M. Del Giudice, A. Lepore, G. Staiano, and M. Martorelli, "On the Geometric Accuracy of RepRap Open-Source Three-Dimensional Printer", Journal of Mechanical Design, vol. 137 , no. 10,2015 DOI: $10.1115 / 1.4031298$.

[10] E. Martelli, et al., "Advancements in DEMO WCLL breeding blanket design and integration", International Journal of Energy Research, vol. 42, no. $1,2018,27-52$ DOI: $10.1002 /$ er.3750.

[11] G. M. Perri, M. Bräunig, G. Di Gironimo, M. Putz, A. Tarallo, and V. Wittstock, "Numerical modelling and analysis of the influence of an air cooling system on a milling machine in virtual environment", International Journal of Advanced Manufacturing Technology, vol. 86, no. 5, 2016, 1853-1864 DOI: $10.1007 / \mathrm{s} 00170-015-8322-5$.

[12] G. Di Gironimo, A. Lanzotti, D. Marzullo, G. Esposito, D. Carfora, and M. Siuko, "Iterative and Participative Axiomatic Design Process in complex mechanical assemblies: case study on fusion engineering", International Journal on Interactive Design and Manufacturing, vol. 9, no. 4, 2015, 325-338

DOI: 10.1007 /s12008-015-0270-7.

[13] Lanzotti A., Carbone F., Di Gironimo G., Papa S., Renno F., Tarallo A., D’Angelo R., On the usability of augmented reality devices for interactive risk assessment, International Journal of Safety and Security Engineering, Volume 8 (2018), Issue 1 DOI: 10.2495/SAFE-V8-N1-132-138.

[14] S. Patalano, F. Vitolo, and A. Lanzotti, "A Digital Pattern Approach to 3D CAD Modelling of Automotive Car Door Assembly by Using Directed Graphs". In: S. Zawiślak and J. Rysiński, eds., Graph-Based Modelling in Engineering, Mechanisms and Machine Science, 175-185. Springer, Cham, 2017 DOI: $10.1007 /$ 978-3-319-39020-8_13.

[15] F. Vitolo, S. Patalano, A. Lanzotti, F. Timpone, and M. De Martino, "Window shape effect in a single bowden power window system". In: 2017 IEEE International Systems Engineering Symposium (ISSE), 2017, 1-5 DOI: 10.1109/SysEng.2017.8088308.

[16] F. Renno and S. Papa, "Direct Modeling Approach to Improve Virtual Prototyping and FEM Analyses of Bicycle Frames", Engineering Letters, vol. 23, no. 4, 2015, 333-341.

[17] Crescenzi F. et al.,"Vessel and In-Vessel Components Design Upgrade of the FAST Machine", Fusion Engineering and Design 88 (9-10), pp. 2048-2051, 2013.

[18] G. E. P. Box, W. G. Hunter, and J. S. Hunter, Statistics for Experimenters: An Introduction to Design, Data Analysis, and Model Building, John Wiley \& Sons: New York, 1978.

[19] P. Erto, La Qualità Totale, CUEN: Napoli, 1995.

[20] P. Erto, Probabilità e statistica per le scienze e l'ingegneria, 2nd ed., McGraw-Hill: Milano, 2004. 
[21] U.N. Bhat, Elements of Applied Stochastic Processes, John Wiley \& Sons: New York, 1984. 


\section{APPENDIX A}

Virtual Catalogue of archetypes $^{1}$ (source: Morel 1981)

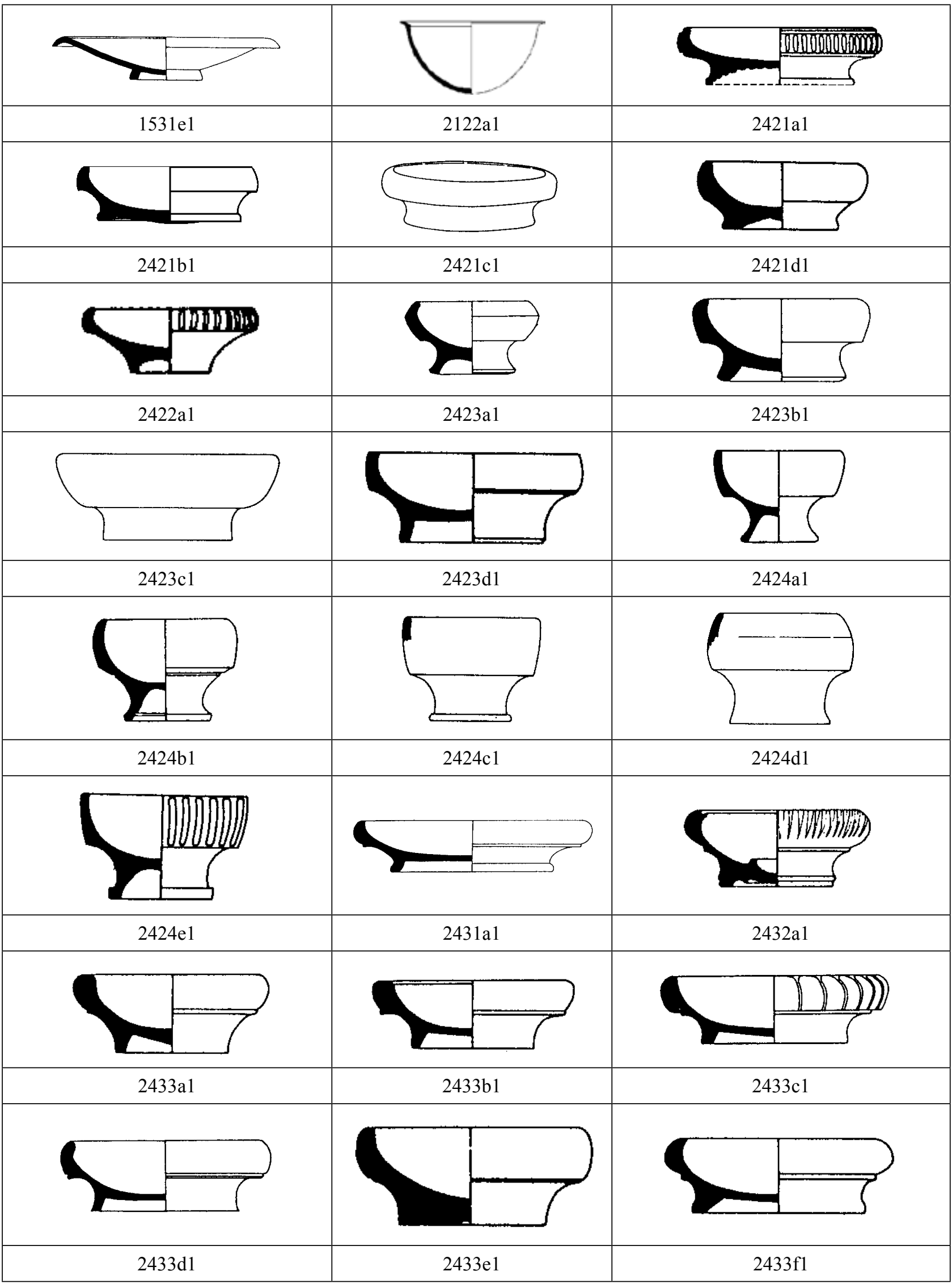

${ }^{1}$ The Archetypes are not shown with the same scale of representation for editorial needs. 


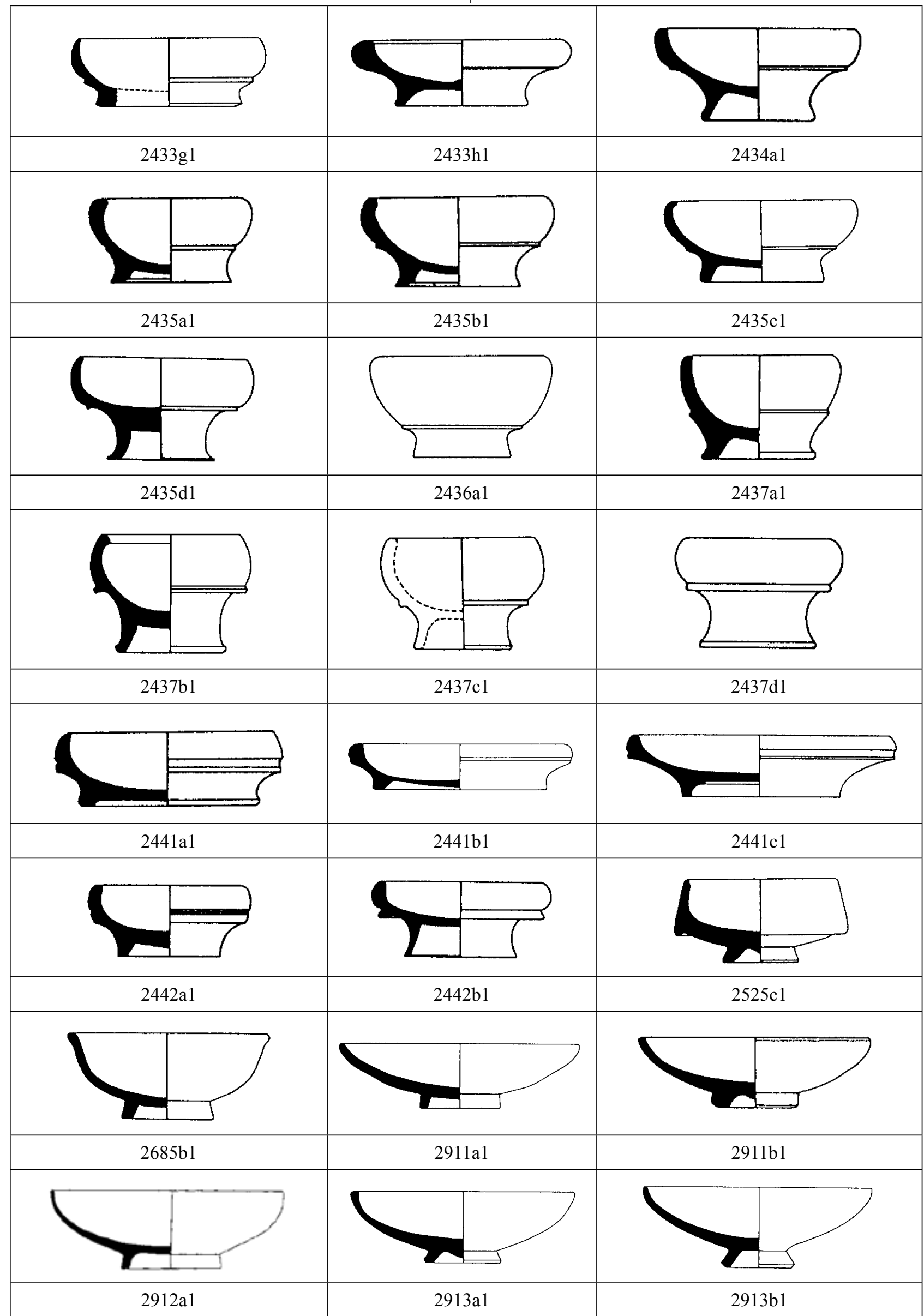




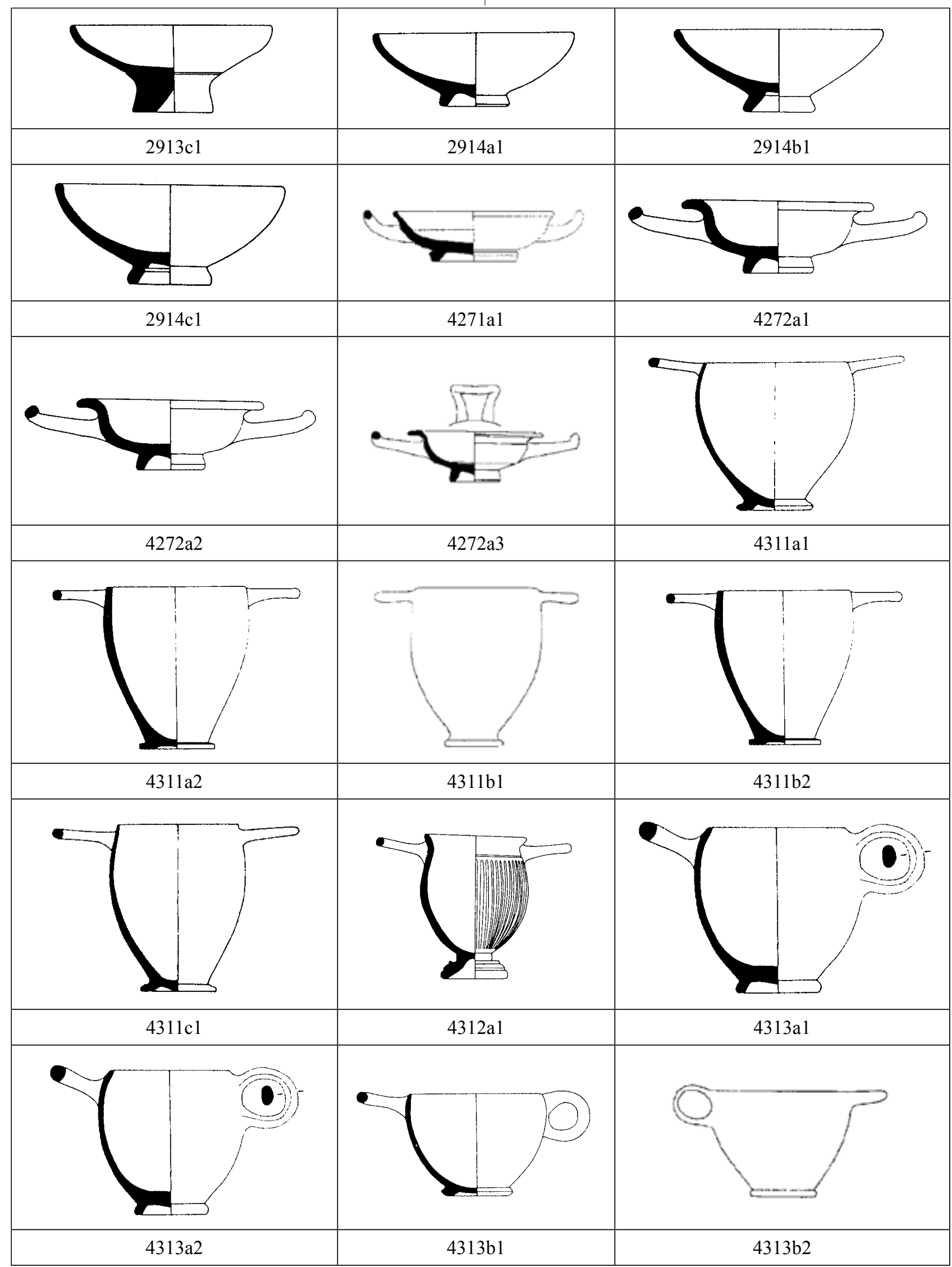




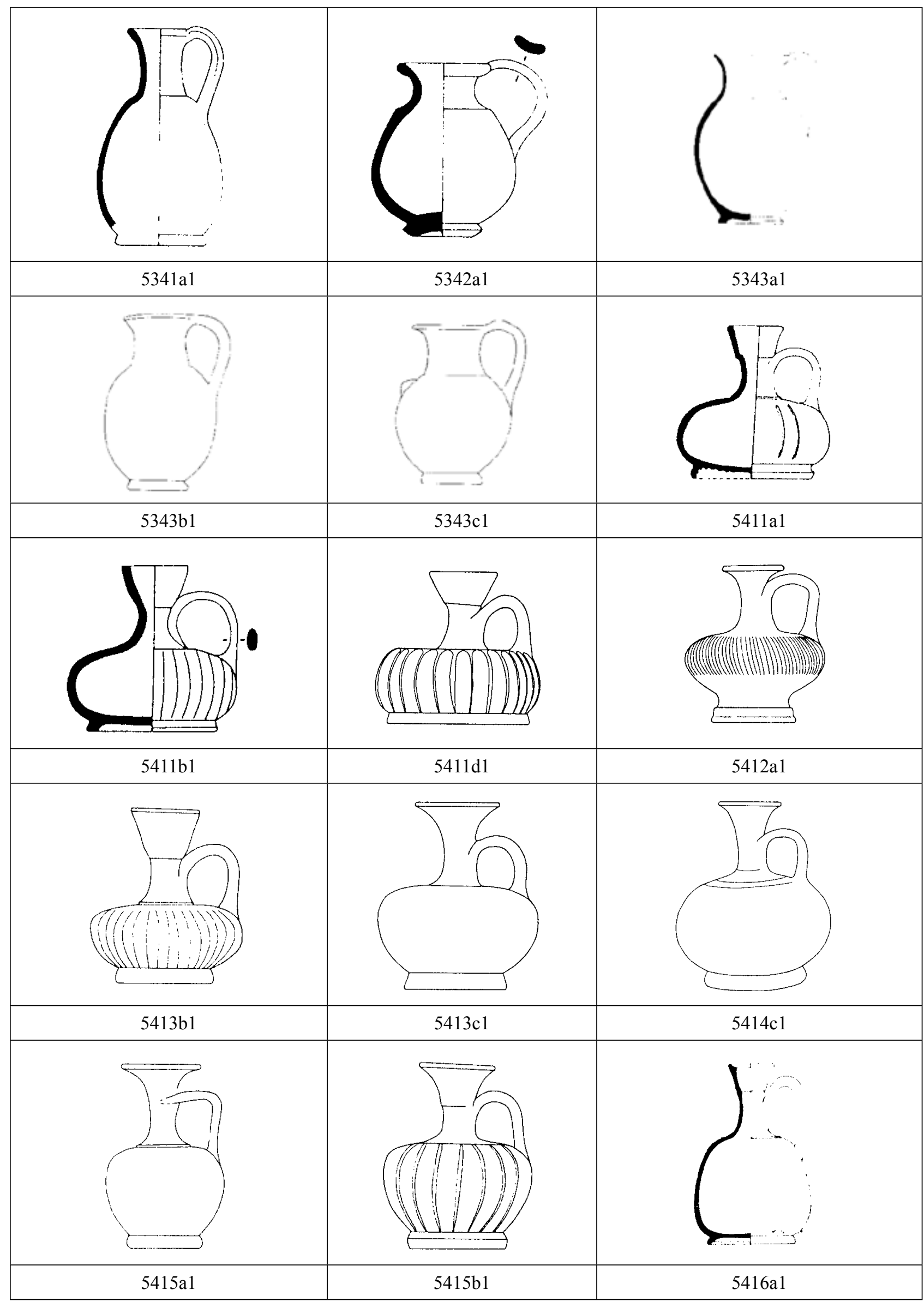




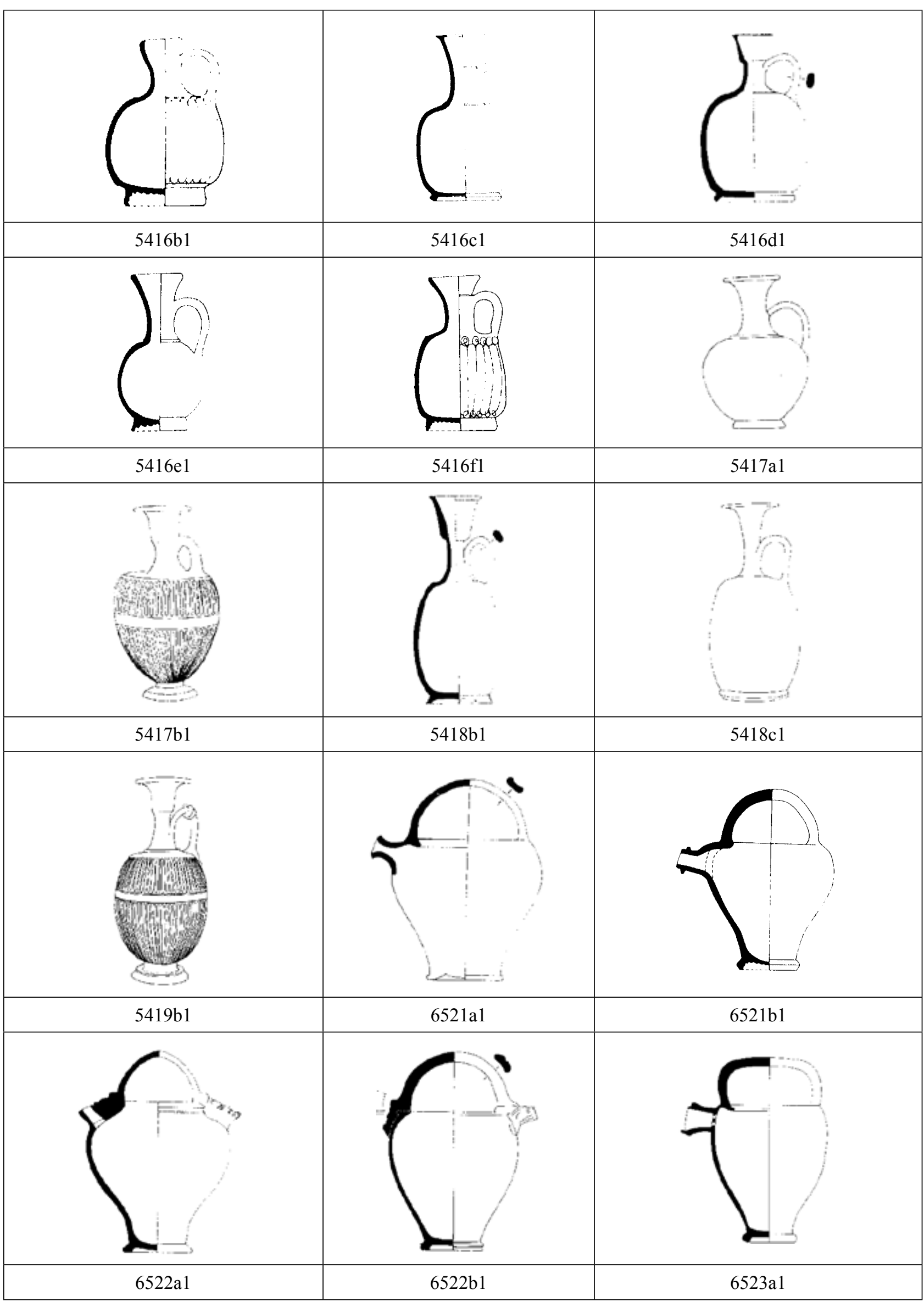




\begin{tabular}{|c|c|c|c|}
\hline & \\
\hline & & \\
\hline
\end{tabular}

\section{APPENDIX B}

Virtual Catalogue of the vectorized profiles

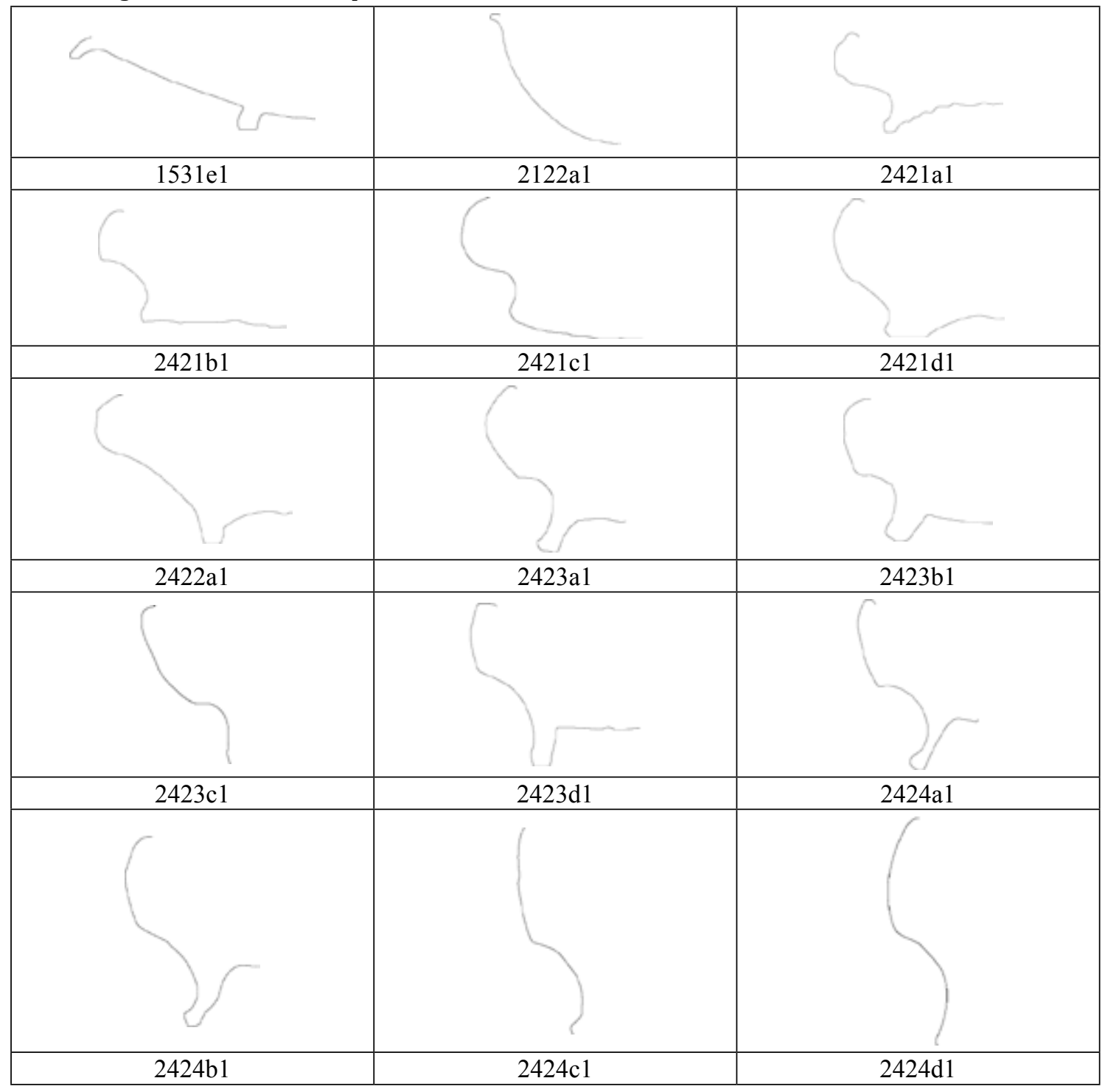




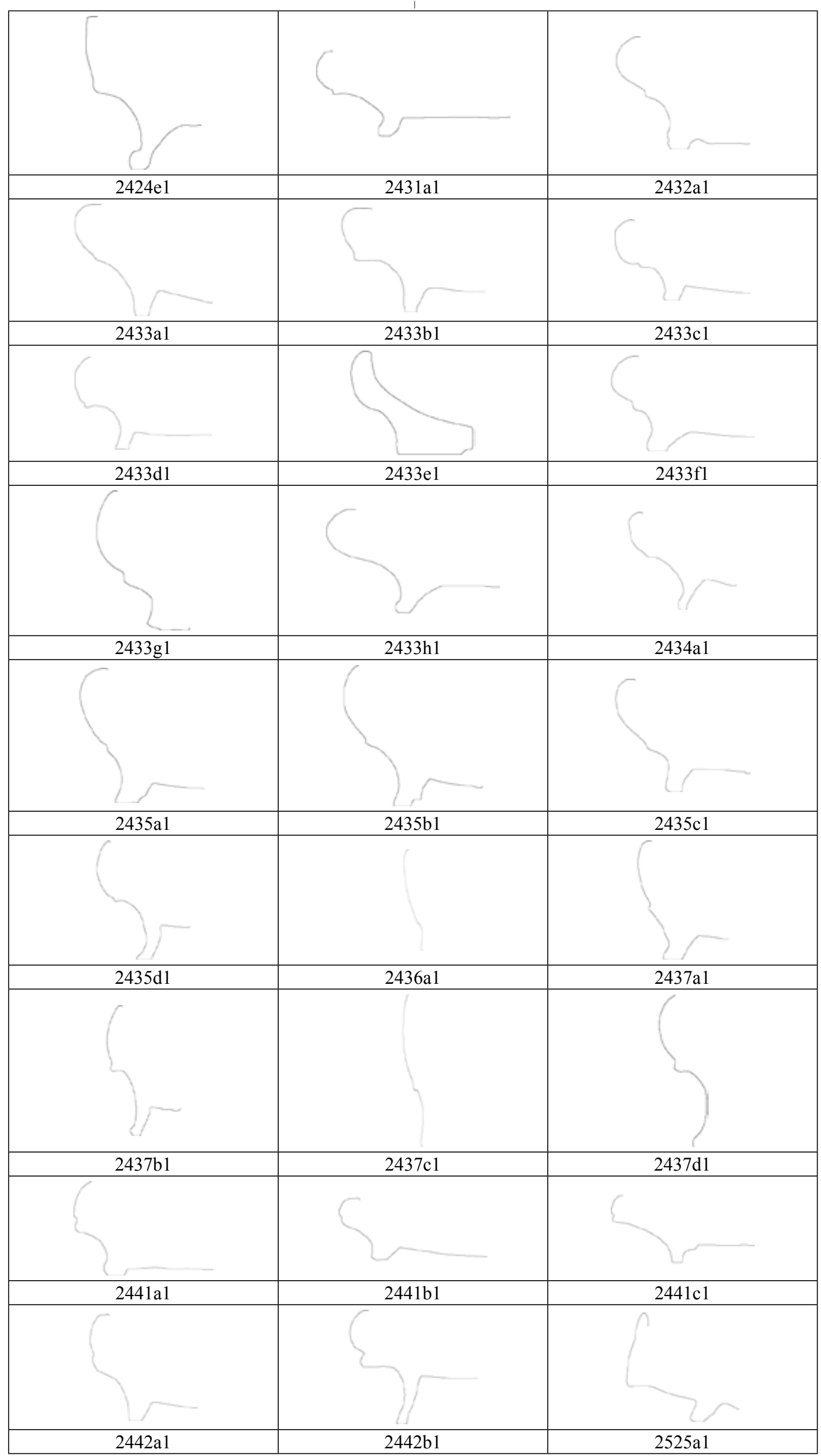




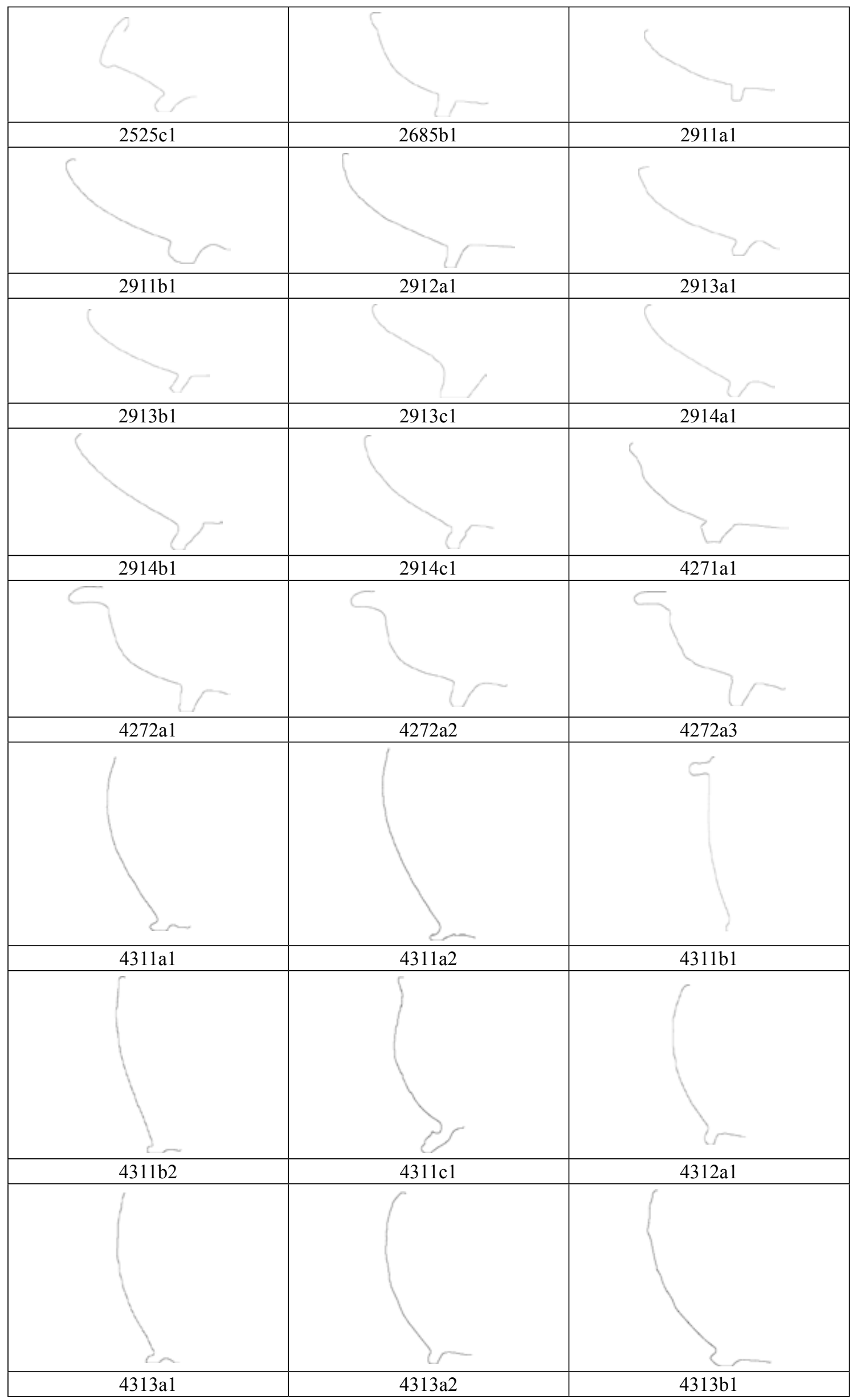




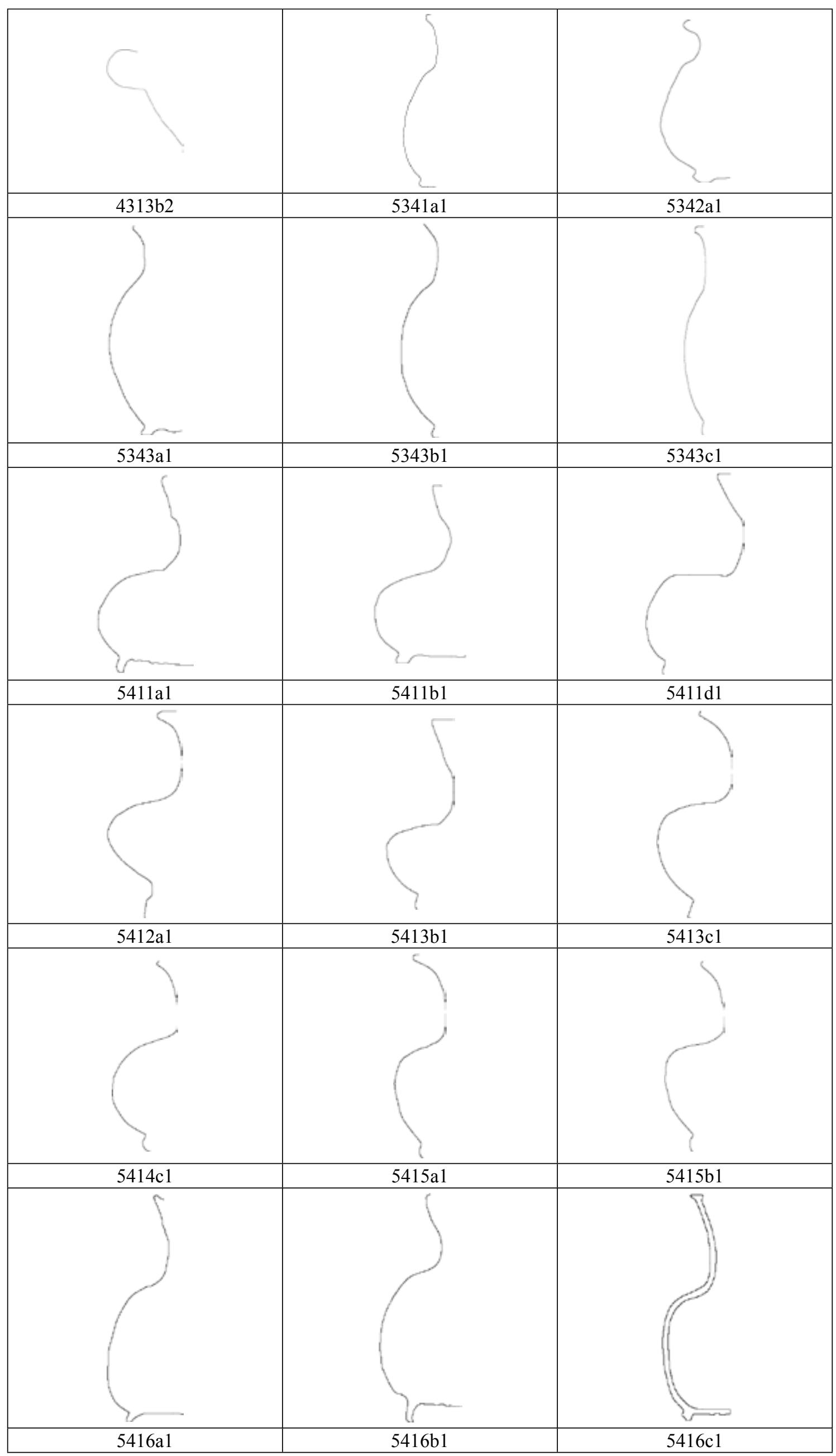


Journal of Automation, Mobile Robotics and Intelligent Systems

VOLUME 13, N¹ 2019

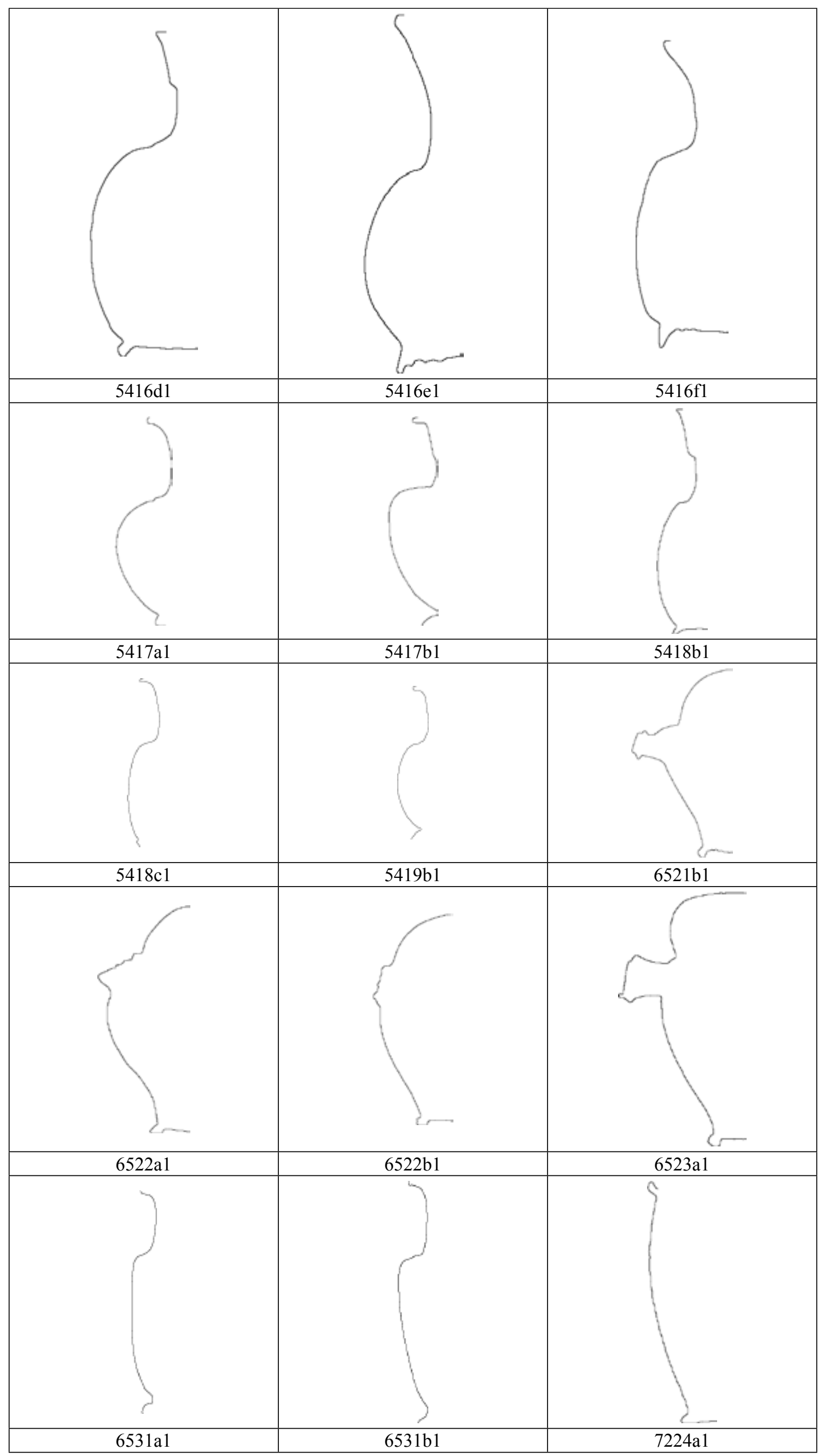

64 